\title{
Model of potential distribution of Platymeris rhadamanthus Gerstaecker, 1873 with redescription of species
}

\author{
Dominik Chłond ${ }^{*}$ and Agnieszka Bugaj-Nawrocka
}

\begin{abstract}
Background: The redescription of Platymeris rhadamanthus Gerstaecker, 1873 as well as the designation of lectotype and paralectotype, plus the prediction of the potentially suitable habitat was the main goal of this study. Our research were based on 262 specimens of museum collections of $P$. rhadamanthus species and a set of 23 environmental predictor variables, all recorded in a $1 \times 1 \mathrm{~km}$ grid covering Africa. Ecological niche modelling was performed using the MAXENT analyses to produce predictive potential distribution maps for this species and its colour forms separately.

Results: The results suggested the most suitable areas of distribution of $P$. rhadamanthus, both for species as a whole and also for the colour forms. A jackknife test showed that the precipitation of coldest quarter and herbaceous vegetation were the most important environmental variables affecting the distribution of $P$. rhadamanthus. After analyzing the climatic preferences, this species seems to be related mainly to the tropical savanna climate, subtropical highland variety of the oceanic climate and humid subtropical climate. An analysis of environmental variables also showed that this species prefers areas with herbaceous vegetation, with a small participation of trees, which is probably caused by food preferences of its victims.

Conclusions: $P$. rhadamanthus so far was only known that it occurs in widely understood tropical Africa. On the base of the museum data on the occurrence of the species and ecological niche modelling methods we provided new and valuable information of the potentially suitable habitat, the possible range of distribution of the species and its climatic preferences.
\end{abstract}

Keywords: Africa; Ecological niche modelling; Habitat suitability; Maximum entropy; Species distribution

\section{Background}

The genus Platymeris was established by Laporte (1833) and with thirteen described species it is a medium-sized genus belonging to the subfamily Reduviinae. All known species of these assassin bugs are large-sized insects, distributed exclusively in Africa (Maldonado Capriles, 1990). Platymeris rhadamanthus have been described by Gerstaecker (1873) on the basis of specimens collected in Zanzibar (two syntypes), this species is however widely distributed in the tropical part of continental Africa. Due to the availability of a large number of individuals of this species deposited in European museum collections and thorough examination of the morphology of the species,

\footnotetext{
* Correspondence: dominik.chlond@us.edu.pl

Department of Zoology, Faculty of Biology and Environmental Protection, University of Silesia, Bankowa 9, 40-007 Katowice, Poland
}

the redescription and designation of the lectotype and paralectotype is provided. Still, Gerstaecker's description contains only information about the specimens with orange spots on the hemelytra, while during the preparation of the revisionary work of this genus two colour forms of these insects have been identified and the second one (with red spots on hemelytra) is the form described by Distant (1878) as P. confusa. Individuals representing the type material belong to the form of orange-colored spots on the hemelytra, but a second form with red spots on the hemelytra has also been encountered. P. rhadamanthus can be easily recognized amongst the other representatives of this genus by the coloration of the spots on the hemelytra (orange and red) and bands on legs (red). The mentioned species has a very similar colour pattern as two other representatives of this genus: P. erebus Distant, 1902 (red spots on the hemelytra and black 
pale patterns on femurs) and P. biguttatus (Linnaeus, 1767) (white spots on the hemelytra and yellow band on femurs).

A thorough analysis of the distribution of both colour forms of $P$. rhadamanthus showed that they occur in different environmental niches. In order to gain more information about some ecological aspects of this species, was decided to introduce ecological niche modelling into our study. Using this method allows for a number of activities within the scope of biogeography: the identification of potential migration routes of invasive species, the planning of protected areas or predicting the effects of climate change (Araújo et al., 2005; Jeschke \& Strayerb, 2008; Zhu et al., 2012). The distribution of species is often poorly known, in particular in the case of tropical ones. Many factors (both biotic and abiotic) affected this distribution. They are not only determinants of suitable habitat but also constitute limiting barriers. This study is an attempt to answer the questions: which environmental niches may potentially be suitable for $P$. rhadamanthus, and whether there are differences in habitat preferences of colour forms. For this purpose, the MAXENT (the maximum entropy model) software was employed. It is based on machine learning method and thanks to its many advantages it seems to be a well-suited method for species distribution modelling (Phillips et al., 2006). As it is reported by research studies, MAXENT seems to have a better performance and work better than other software in predicting the distribution of species, especially in the case of limited number of sample localities (Elith et al., 2006; Hernandez et al., 2006; Pearson et al., 2007). We also took advantage of the jackknife test built-in to MAXENT. As it weighs the relative contribution of each environmental variable, it was deemed a convenient tool for evaluating predictors. Through these studies we demonstrate detailed redescription of $P$. rhadamanthus and what are the differences in the preferences of the ecological niche of its both colour forms.

\section{Methods}

\section{Taxonomy}

External structures of dry-mounted specimens were examined using a stereoscopic microscope Olympus SZH10. All drawings were made using a camera lucida. Genitalia were boiled in $10 \% \mathrm{KOH}$ for 5 minutes to remove soft tissue, rinsed in distilled water and dissected under the stereoscopic microscope Olympus SZH10. Dissected genitalia are stored in PVC microvials with glycerol, attached on the pin with the dissected specimen. Measurements are given in millimeters.

Quoting the labels of specimens: (/) is used to divide data on different rows on the label, (;) is used to divide data on different labels, ([]) is used for authors comments, $(*)$ specimens collected on unspecified location.
Abbreviations for depositories: (BMNH) - The Natural History Museum, London, United Kingdom; (IRSNB) Institut Royal des Sciences Naturelles de Belgique, Bruxelles, Belgium; (MNHN) - Muséum National d'Histoire Naturelle, Paris, France; (MRAC) - Musée Royal de l'Afrique Centrale, Tervuren, Belgium; (NHRS) - Naturhistoriska Riksmuseet, Stockholm, Sweden; (NMW) - Naturhistorische Museum, Wien, Austria; (ZMB) - Museum für Naturkunde, Berlin, Germany.

\section{Occurrence data}

A total of 90 occurrence localities were assembled for the species $P$. rhadamanthus. There were 48 points for the orange form and a 42 points for the red form. All occurrence data is based on the detailed review of 262 specimens studied in the museum collections (see abbreviations for depositories). This species has been localized in the Democratic Republic of Congo, Burundi, Kenya, Tanzania, Angola, Zambia, Malawi, Mozambique and South Africa (Figure 1a). Records with unspecified or unknown localities were not used. All localities were georeferenced using Google Earth 6.2 (Google Inc 2013, Mountain View, CA, USA) (geographical projection, decimal degrees, datum: WGS84).

\section{Environmental predictors}

Environmental variables were used as potential predictors of habitat distribution for this species. The study was based on 19 bioclimatic variables derived from the WorldClim 1.4 dataset (Hijmans et al., 2005; http://www.worldclim.org/ bioclim). A digital elevation model (DEM) was downloaded from the Global Land One-km Base Elevation Project (GLOBE) (GLOBE Task Team and others 1999; http:// www.ngdc.noaa.gov/mgg/topo/globe.html). Layers of the Vegetation Continuous Fields were also used. This collection contains vegetative cover types such as tree vegetation, herbaceous vegetation and bare ground (Hansen et al., 2003; http://glcf.umd.edu/data/vcf). All of the variables were cut to the boundaries of Africa. A spatial resolution of 30 arc-seconds $(\sim 1 \mathrm{~km})$ was chosen.

\section{Climate classification}

Climatic preferences were defined on the basis of KöppenGeiger climate classification system which has been updated by Peel et al. (2007).

\section{Ecological niche modelling}

All species distribution models were developed using the MAXENT software (version 3.3.3e), which is based on a maximum entropy algorithm. Default settings were chosen: maximum number of background points $=10.000$, regularization multiplier $=1$, convergence threshold $=$ 0.00001 and a maximum number of iterations $=500$. From the occurrence data $70 \%$ was used as the training 


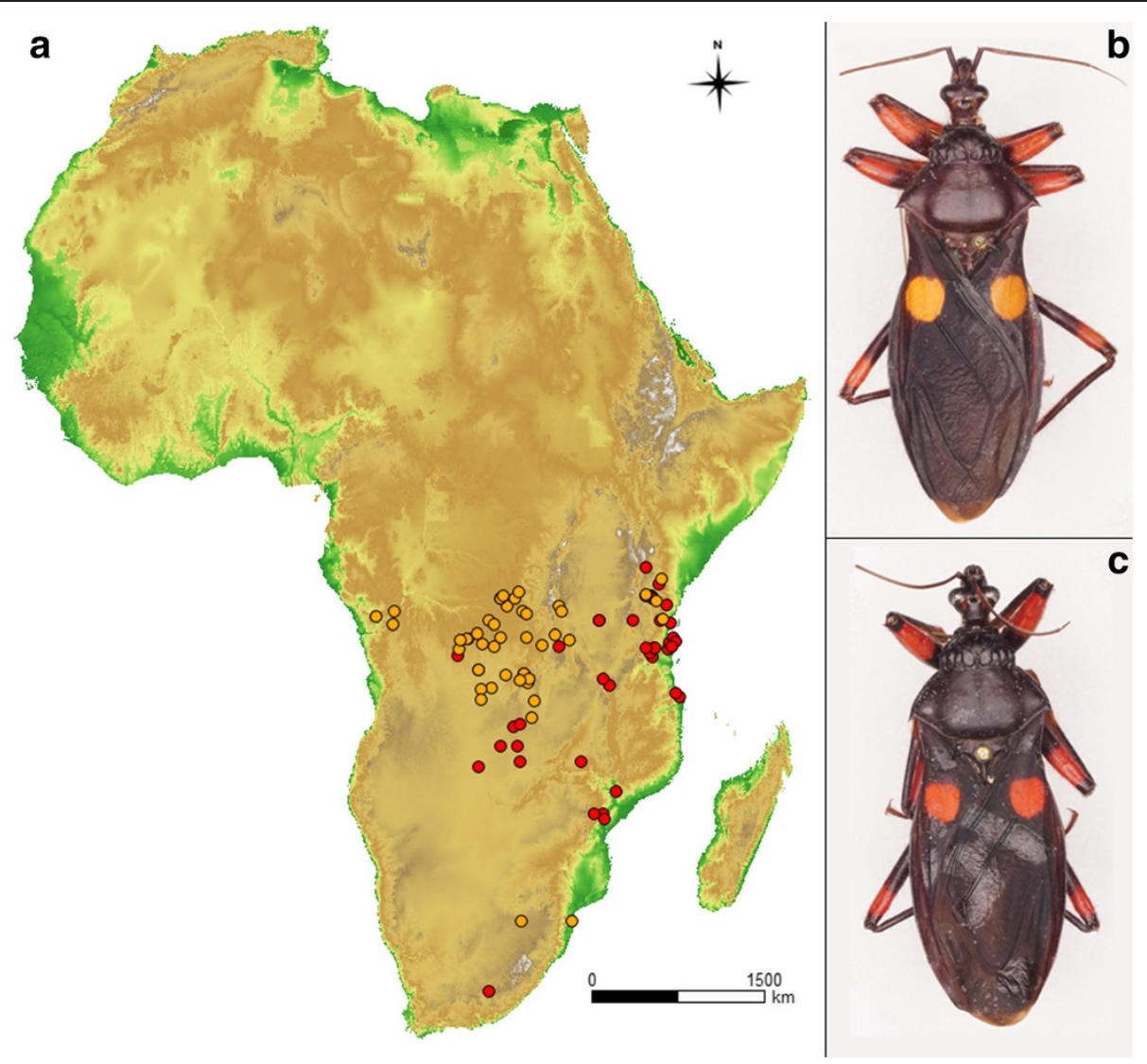

Figure 1 Distribution of $P$. rhadamanthus and dorsal habitus of both colour forms. a - Map shows known distribution points for $P$. rhadamanthus, divided into an orange and red colour form, based on the identified museum data; $\mathbf{b}$ - Dorsal habitus of orange form of $P$. rhadamanthus Gerst.; c - Dorsal habitus of red form of P. rhadamanthus Gerst.

data set and $30 \%$ was used as the test data set. The logistic output of MAXENT with prediction values ranging from 0 (unsuitable habitat) to 1 (optimal habitat) was used. Several techniques to evaluate the MAXENT model were applied. From amongst the additions implemented in MAXENT, a jackknife test was selected. It is a test comparing models with all combinations of the environmental variables by measuring variable importance, so it shows the relative importance of each predictor variable. A receiver operating characteristic (ROC) analysis was also used to assess the quality of the model (Fielding \& Bell, 1997). A sensitivity is located on the ordinate, which is equal to the proportion of test localities correctly predicted as present. On the abscissa ( 1 - specificity) is located, which is the proportion of all map pixels which are predicted to have suitable conditions, called a false positive. The AUC was also calculated - a measure of the area under the ROC curve that shows the performance of the model and a weight of the omission error and commission error equally. The AUC takes values range from 0 to 1 , however the useful models produce AUC values from 0.7 to 0.9 , and AUC values above 0.9 characterized models with almost perfect discrimination (Fielding \& Bell, 1997; Pearce \& Ferrier, 2000). At the beginning, for each form of species and for all occurrence localities together, modelling with all environmental variables was carried out and 25 replicates was selected. In order to minimize the number of variables, the Pearson correlation was performed. At first, ENM Tools 1.3 software (Warren et al., 2008) was used for an analysis of the correlation for all obtained raster layers. Then raw environmental data was extracted from all raster layers at species occurrence records using SAGA GIS 2.0.8 (SAGA Development Team, 2013) and for those data, in the R software (R Development Core Team, 2011) using Rattle package (version 2.6.25) (Williams, 2011), an analysis of the correlation and principal component analysis (PCA) were also performed. After the analysis of results, the variables that did not have any significant contribution to the model were removed, and six variables were selected for $P$. rhadamanthus. Finally, six variables were selected for the orange form and five for the red form (Table 1). In the final modelling, 50 model replicates were run. 
Table 1 Variables selected for the final modelling

(a) P. rhadamanthus (both colour forms)

\begin{tabular}{|c|c|c|c|c|c|}
\hline \multirow[t]{2}{*}{ Variables } & \multirow[t]{2}{*}{ Description } & \multicolumn{4}{|c|}{ Occurrences } \\
\hline & & Min. & Median & Mean & Max. \\
\hline Bio05 & $\begin{array}{l}\text { Maximal temperature } \\
\text { of warmest month }\end{array}$ & 22.4 & 31.5 & 31.3 & 35.8 \\
\hline Bio07 & Temperature annual range & 11.3 & 16.2 & 17.2 & 29.4 \\
\hline Bio12 & Annual precipitation & 436 & 1159 & 1190 & 1909 \\
\hline Bio15 & $\begin{array}{l}\text { Precipitation seasonality } \\
\text { (coefficient of variation) }\end{array}$ & 44 & 77 & 77.3 & 116 \\
\hline Bio19 & $\begin{array}{l}\text { Precipitation of coldest } \\
\text { quarter }\end{array}$ & 0 & 43 & 58.6 & 545 \\
\hline Herb. & Herbaceous vegetation & 55 & 76 & 75 & 100 \\
\hline
\end{tabular}

(b) Orange form of $P$. rhadamanthus

\begin{tabular}{llcccc}
\hline Variables & Description & \multicolumn{4}{c}{ Occurrences } \\
\cline { 3 - 6 } & & Min. & Median & Mean & Max. \\
\hline Bio02 & Mean diurnal range & 8.3 & 11.3 & 11.6 & 15.1 \\
Bio10 & $\begin{array}{l}\text { Mean temperature of } \\
\text { warmest quarter }\end{array}$ & 16 & 24.7 & 24.3 & 26.7 \\
Bio12 & Annual precipitation & 562 & 1348 & 1275 & 1674 \\
Bio15 & $\begin{array}{l}\text { Precipitation seasonality } \\
\text { (coefficient of variation) }\end{array}$ & 44 & 72 & 70 & 116 \\
Bio18 & $\begin{array}{l}\text { Precipitation of warmest } \\
\text { quarter }\end{array}$ & 100 & 383 & 360 & 568 \\
Herb. & Herbaceous vegetation & 55 & 76 & 75 & 94 \\
\hline
\end{tabular}

(c) Red form of $P$. rhadamanthus

\begin{tabular}{llcccc}
\hline Variables & Description & \multicolumn{4}{c}{ Occurrences } \\
\cline { 3 - 6 } & & Min. & Median & Mean & Max. \\
\hline Bio05 & $\begin{array}{l}\text { Maximal temperature } \\
\text { of warmest month }\end{array}$ & 26.8 & 31.9 & 31.7 & 35.8 \\
Bio12 & Annual precipitation & 436 & 1033 & 1093 & 1909 \\
Bio15 & $\begin{array}{l}\text { Precipitation seasonality } \\
\text { (coefficient of variation) }\end{array}$ & 55 & 88 & 86 & 114 \\
Bio19 & Precipitation of coldest quarter & 2 & 44 & 55 & 204 \\
Herb. & Herbaceous vegetation & 57 & 75 & 74 & 100 \\
\hline
\end{tabular}

Variables with explanations and altitude ranges for the localities with occurrence of (a) P. rhadamanthus and its (b) orange and (c) red colour forms: temperatures given in ${ }^{\circ} \mathrm{C}$, precipitations given in $\mathrm{mm}$, vegetation cover (Herb. = Herbaceous) given in \%.

\section{Results and discussion \\ Results}

\section{Taxonomy}

Genus: Platymeris Laporte, 2: 80, (in Guérin).

Type species: Cimex biguttatus Linnaeus, 1767: 725. By monotypy.

Platymeris rhadamanthus Gerstaecker, 1873 (Figures 1b-c, 2, 3a-p).

Platymeris confusa Distant, 1878: 100. Synonimized by Jeannel, 1919: 238.

Hermillus confusus Schouteden, 1906: 24.

Type material examined: Lectotype, $\hat{\sigma}$, (present designation): 9111 [printed]; Typus [printed on red label];

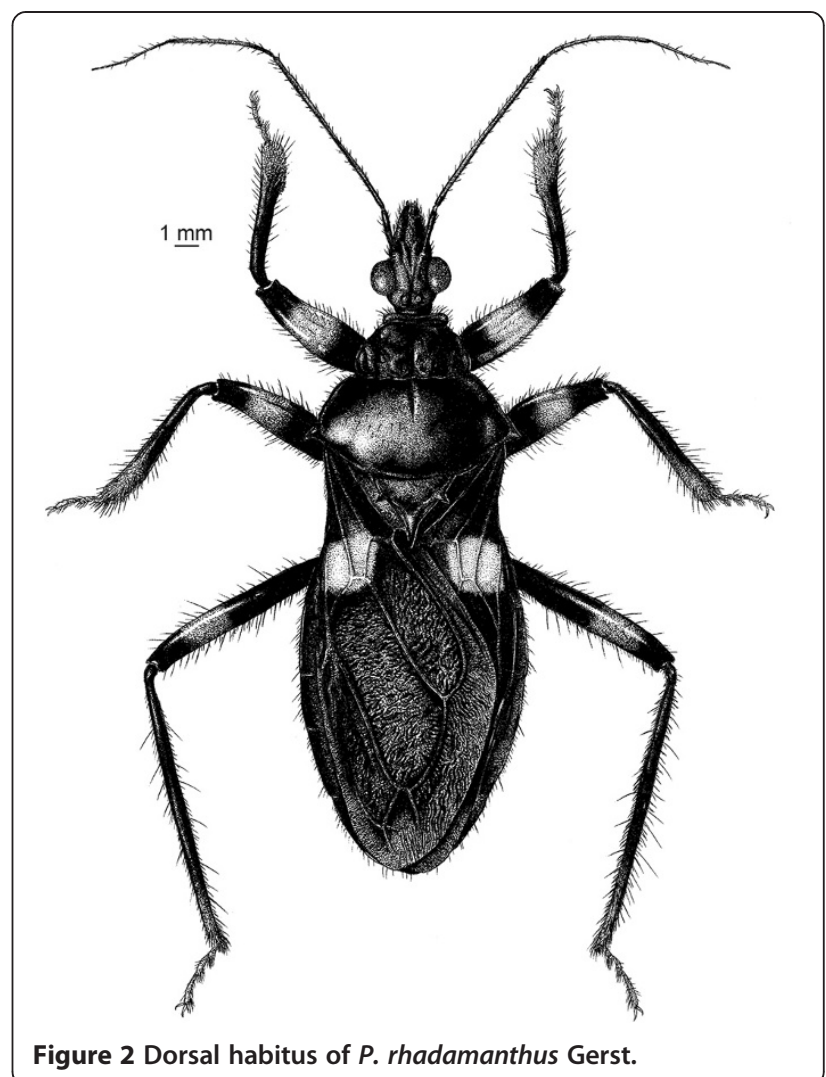

Endara / v. D. Decken / No. 9111 [handwritten]; Platymeris / Rhadamanthus / Gerst * [handwritten] (ZMB). Paralectotype, , (present designation): Typus [printed on red label] / Endara / v. D. Decken / Nr. 9111 [handwritten]; Platymeris / Rhadamanthus / Gerst* [handwritten] (ZMB).

For other examined materials see Additional file 1 .

\section{Redescription}

Colour: Body black or dark brown with pale markings (orange (Figure 1b) or red (Figure 1c)) on the corium and legs (Figures 1b, c, 2) and with dark setation. Head black or dark brown with paler spots between eyes and ocelli. Eyes black (some specimens with pale marginal facets or pale eyes with black irregular spots). Scapus black, pedicellus brown with paler annulus in basal part. Basiflagellomere and distiflagellomere brown. Basal part of second visible labial segment in ventral side as well as third visible labial segment pale. Pronotum and thorax black to dark brown. Legs black to dark brown with wide red annulus on femurs (placed on 1/2 apical part of fore and mid femur, except apex; small annulus in apical part of hind femur). Hemelytra with orange spots placed on middle part of corium and extended also on basal part of apical external and internal cells. Abdomen black to dark brown. Tergites II-V yellowish or reddish with dark lateral margins. Tergite VI black or dark brown with paler middle part of anterior margin. Pygophore black. 

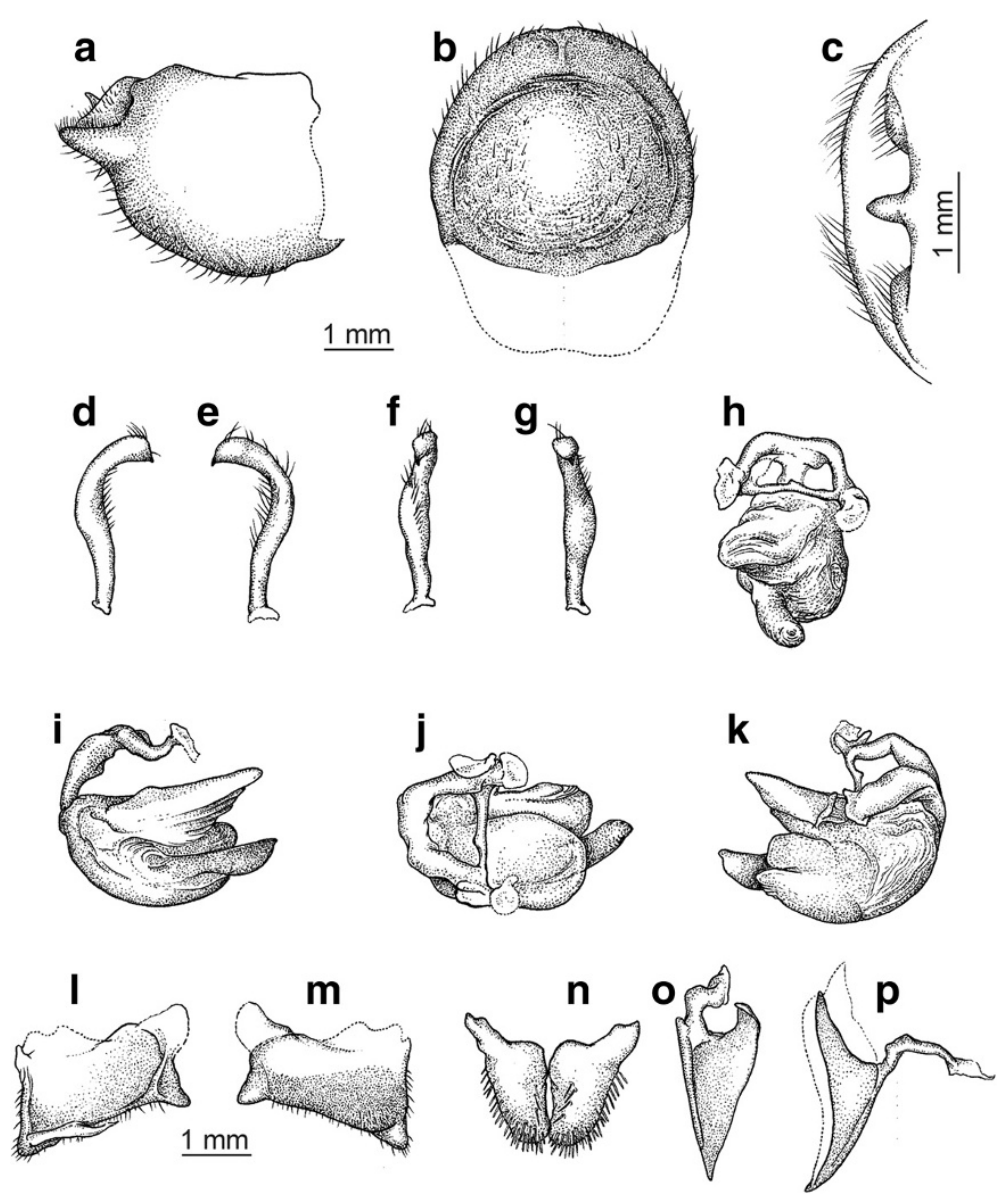

$1 \mathrm{~mm}$

Figure $\mathbf{3}$ Characteristics of male and female genitalia of $\boldsymbol{P}$. rhadamanthus. Male: $\mathbf{a}$ - pygophore, lateral view; $\mathbf{b}$ - pygophore, ventral view; c - pygophore, median process, dorsal view; $\mathbf{d}$ - right paramere, outer view; e - left paramere, outer view; $\mathbf{f}$ - right paramere, lateral view; $\mathbf{g}$ - left paramere, lateral view; $\mathbf{h}$ - phallus, frontal view; $\mathbf{i}$ - phallus, left lateral view; $\mathbf{j}$ - phallus, dorsal view; $\mathbf{k}$ - phallus, right lateral view; Female: $\mathbf{I}$ - valvula 1 and valvifer 1, inner view; $\mathbf{m}$ - valvula 1 and valvifer 1 , outer view; $\mathbf{n}$ - valvula 3; $\mathbf{0}$ - valvula 2 and valvifer 2 , inner view; $\mathbf{p}$ - valvula 2 and valvifer 2, outer view.

Structure: Body large, dull and elongated with various sized setation. Head elongated with medium sized, suberected setae. Eyes large, elongated vertically, not reaching dorsal and ventral margin in lateral view. Ocelli large, placed on large and wide tubercles. Mandibular plates distinctly enlarged and concave in lateral and frontal view. Mandibular plate tongue-like shape, irregularly shaped, with short, suberected setae on apical part. Pedicellus long, slightly curved in basal part with regularly arranged, robust erected setae of various sizes and very dense, short and suberected setae. Basiflagellomere and distiflagellomere thin with long, sparse, erected, regularly arranged setae and very short and dense adherent setae. Clypeus with dense, medium sized setae. Gula covered apically by dense, robust and medium sized setae. Scapus short and robust with short, suberected setae. Labrum as well as dorsal part of all visible labial segment covered by dense, robust setae of various sizes. Ventral side of labial segments covered by sparse setae of various sizes. First visible labial segment subrectangular with narrow apical part on ventral side. Second visible labial segment the longest, with narrow apical part. Third visible labial segment conical, flattened laterally. Second visible labial segment reaching over posterior margin of eyes. Anterior pronotal lobe with small calli placed laterally on collar and with distinct sulci and protuberances. Anterior lobe covered by mostly long and slightly curved setae of various sizes placed only in protuberances. Middle part of anterior pronotal lobe with two lateral protuberances hollowed in the middle; posterior margin with at least eight protuberances (irregular in shape) - on most external protuberances small robust spines visible (which can be present only on one side of lobe or altogether be absent). In the middle of the anterior pronotal lobe visible a longitudinal, depressed line distinctly hollowed in posterior part of lobe. Posterior pronotal lobe flattened and slightly curved 
in the middle with slightly hollowed longitudinal line $2 / 3$ of anterior part. Middle part of posterior margin of posterior pronotal lobe distinctly flattened. Small protuberances visible in anterior part of lateral margins. Post-lateral angles of posterior pronotal lobe with small, distinct spines; apices of spines directed dorso-laterally. Stridulitrum long and thin with rounded apex of process of prosternum and with two calli (covered by very dense, short, erected setae) placed laterally in 1/3 of length. Meso- and metepisternum with dense, erected, rather long and thin setae. Stridulitrum with small, apical nodule. Scutellum with distinct pentagonal ridge, slightly depressed in the middle with long erected setae. Three spines placed marginally on scutellum. Apices of spines directed dorsally. Lateral spines short and robust, apical spine elongated with thin and rounded apex. Legs long and robust with distinct punctuation in place of setae insertion. Fore and mid trochanters and femurs very densely covered by stripe of short, suberected setae with central, bare longitudinal line in the middle. Fore and mid femurs slightly convex dorsally. Hind femurs long and distinctly thinner. Tibiae covered by erected and suberected setae of various sizes (short setae very dense in the apical part of each tibiae). Tarsi with very dense setation, third tarsomere distinctly longer than first and second together. Claws large and widely spread. Hemelytra dull with slightly wrinkled membrane and medium-sized, erected setae in basal part of clavus. Membrana surpassing apex of abdomen. Abdominal sternites with distinct punctuation and sculpture (transversal, irregular lines). Abdominal sternites and connexives covered by sparse, suberected setae of various sizes. Pygophore covered by short, erected or suberected setae (Figure $3 \mathrm{~b}$ ).

Genitalia: Male: Middle process of pygophore short, tongue-like with rounded apex (Figure 3a, c). Both parameres long and distinctly curved in apical part (Figure 3d, e). Apices of parameres small and sharp. Both parameres with dense, mostly long setae of various sizes (Figure 3d-g). Phallosoma short and robust (Figure 3i-l). Dorsal phallotecal sclerite tongue-like and wide (Figure 3j). Lateral endosomal processes asymmetrical (left process distinctly larger, reaching over the tip of endosoma) (Figure 3i-l).

Female: Valvula 1 and valvifer 1 with dense, short, erected and robust setae on the posterior margin (Figure 3l, m). Valvula 2 and valvifer 2 slightly convolute (Figure 3o, p). Valvula 3, with very dense, short, erected and robust setae in apical part (Figure 3n).

Measurements (in $\mathrm{mm}$, females in parentheses): Body length: 37.8-40.3 (38.5-39.4); maximum width of abdomen: 10.7-12.1(12.4-13.8); head length: 6.1-6.4 (6.3-6.9); head width: 4.15-4.8 (4.25-4.45); length of anteocular part: 2.72.8 (2.9-3.2); length of postocular part: 1.4-1.8 (1.5-2.1); length of synthlipsis: $1.75-1.8$ (1.8-1.95); interocellar distance: 0.3-0.45 (0.4-0.55); lengths of antennal segments
I:II:III:IV: 2.4-3.1 (2.4-2.6): 9.6-10.65 (8.9-10.2): 5.7-5.8 (5.15-5.85): 4.1-4.4 (3.85-4.05); lengths of rostral segments I: II:III: $2.5-3.5$ (2.9-3.4): 2.6-2.75 (2.55-3.2): 1.6-2.1 (1.8-2.05); maximum length of anterior pronotal lobe: 3.4-4.1 (3.6-3.8); maximum length of posterior pronotal lobe: 5.45-6.2 (5.6-6.1); maximum width of anterior pronotal lobe: 6.05-6.8 (6.2-6.8); maximum width of posterior pronotal lobe: 11.6-12.3 (11.2-12.7); length of scutellum: 3.9-4.45 (3.9-4.25); length of hemelytra: 24.9-25.8 (25.8-27.9).

Remarks: The both colour forms have same morphological characters including the morphology of male and female genitalia.

\section{Evaluation of model and the importance of environmental predictors}

MAXENT had a high level of accuracy of predictions, which suggests an average of AUC at the level of 0.927 . The standard deviation is 0.011 , that is $1.1 \%$. In modelling of the red form an AUC at the level of 0.923 (SD $=0.022$ which is $2.2 \%$ ) was obtained, and for the orange form an AUC $=0.943$ ( $\mathrm{SD}=0.012$ which is $1.2 \%$ ) (Additional file 2). The jackknife test showed that the precipitation of coldest quarter (Bio19) followed by herbaceous vegetation, are the environmental variables with highest gain when used in isolation. It means that those layers have the most useful information by themselves. On the other hand, the annual precipitation (Bio12) and the maximum temperature of the warmest month (Bio05), are the variables that decrease the gain the most when they are omitted, which means that they have a significant portion of information that is not contained in the other variables (Figure 4). Figure 5 shows how the distribution of occurrence records for $P$. rhadamanthus and its colour forms refers to used predictors.

\section{The potential species distribution}

The resulting maps are the median of 50 model replicates. The median was chosen because it is much more resistant to outliers as average than the arithmetic mean. Also because the logistic output was used and the result in values ranging from 0 to 1 was given, it was decided to create an output map with four ranges of presence probability of suitable habitat: $0-25 \%$ as unsuitable habitat, $25-50 \%$ as acceptable habitat, $50-75 \%$ as quite suitable and over $75 \%$ as suitable habitat (Figure 6) (Additional file 3). Figure 7 shows the distribution of the known places of occurrence of this species on the background of the predicted suitable habitats.

Results suggested that the most suitable areas for P. rhadamanthus were mainly restricted to the southern half of the Democratic Republic of Congo and Congo, northern half of Angola, almost the whole area of Tanzania (excluding the central part), southeast Kenya, eastern coast and central part of Mozambique, Burundi, eastern part of 

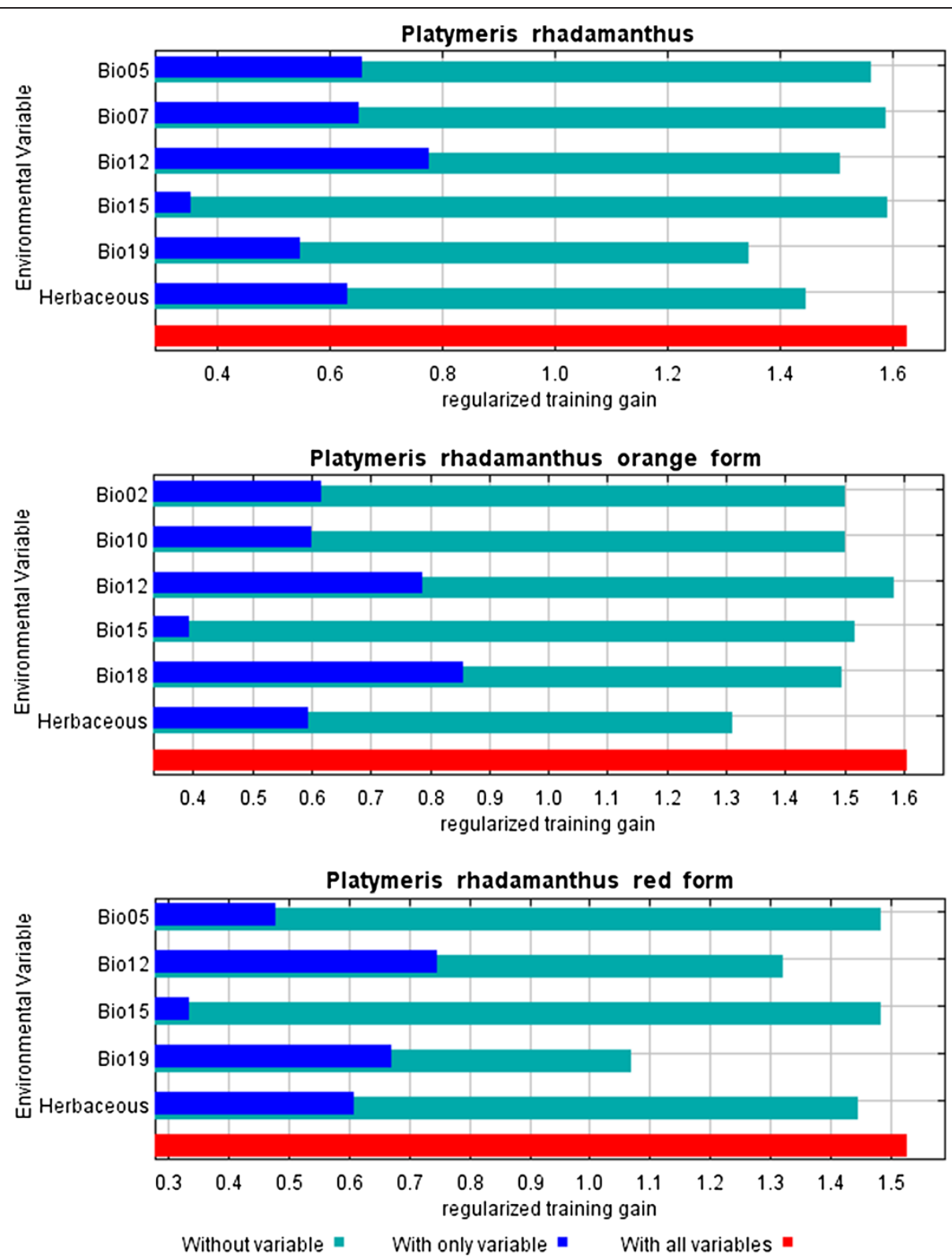

Figure 4 Results of jackknife test of variable importance for the $P$. rhadamanthus and its colour forms. The jackknife test in blue bars shows individual environmental variable importance relative to the red bar which shows all environmental variables. Light blue bar shows whether a variable has any information that isn't present in the other variables, and a dark blue bar shows whether a variable has any useful information by itself. Values shown are averages over replicate runs.

Rwanda, the southern part of Uganda, northern parts of Zambia, Malawi (mostly the southern part and close to Lake Malawi), eastern coast of South Africa, central part of Ethiopia, the southern part of Central African Republic, coast of Ghana, Togo and Benin, and also parts of Cameroon, Gabon and Guinea.

Projected niche spaces in the aspect of whole area of Africa The ranges of the six environmental variables in the distribution area of $P$. rhadamanthus and its colour forms may differ from those in the whole study area. Figure 8 shows how ranges of the temperature and precipitation of the occurrence localities look on the background of the whole continent. The dark gray bars represent variables of the localities where the species occurs, while the light gray bars are computed for the whole area of Africa. The mean temperature in the warmest month is $35.7^{\circ} \mathrm{C}\left(96.26^{\circ} \mathrm{F}\right)$ in the study area, while the mean variable is $31.3^{\circ} \mathrm{C}\left(88.34^{\circ} \mathrm{F}\right)$ in the distribution area of $P$. rhadamanthus. For the orange form the mean is $30.9^{\circ} \mathrm{C}\left(87.62^{\circ} \mathrm{F}\right)$ and $31.7^{\circ} \mathrm{C}\left(89.06^{\circ} \mathrm{F}\right)$ for 

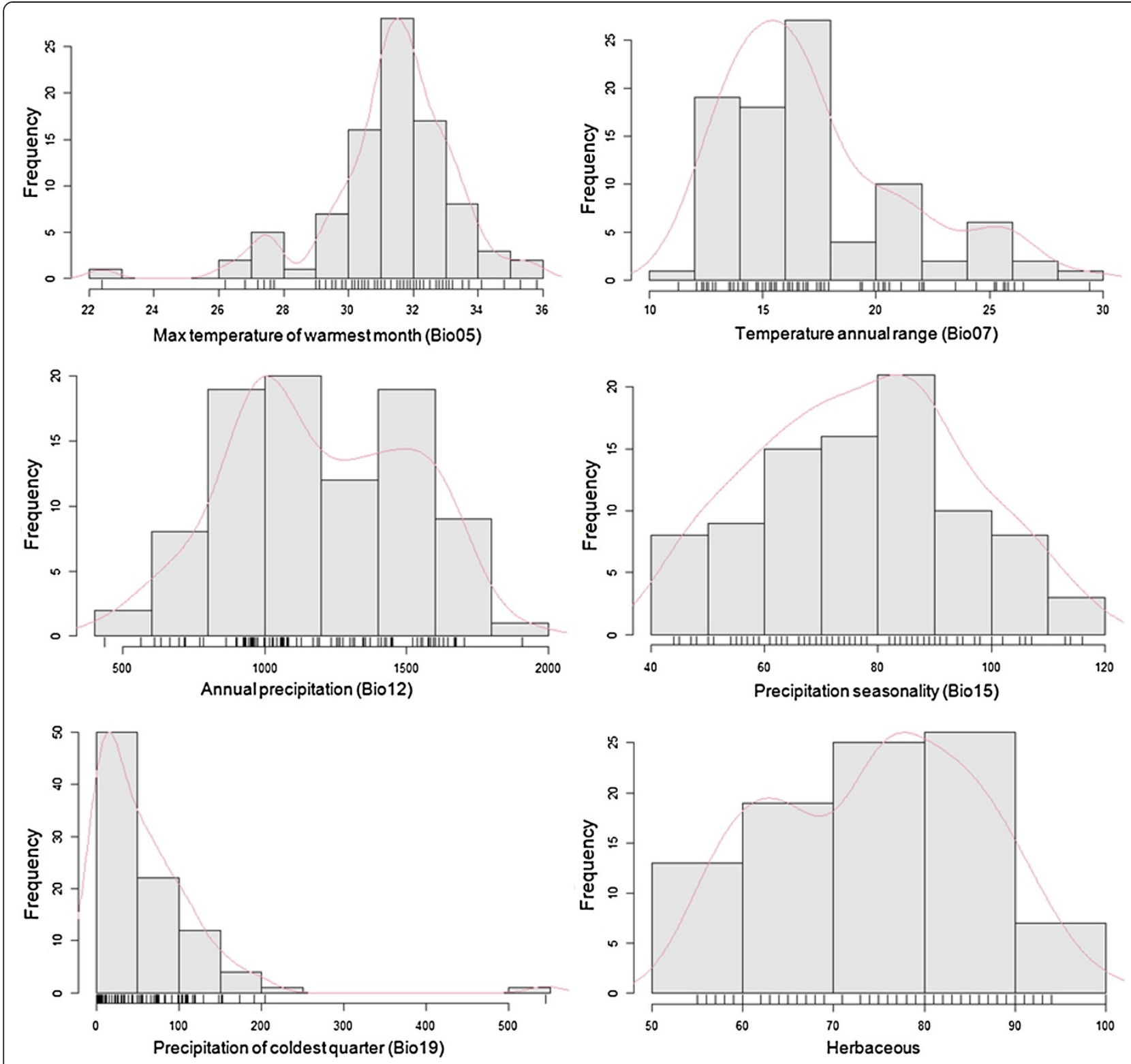

Figure 5 Distribution of the occurrence records for $P$. rhadamanthus in relation to used predictors. The temperature data given in ${ }^{\circ} \mathrm{C}$; the unit used for the precipitation data is $\mathrm{mm}$; vegetation cover given in \%.

the red one. The annual precipitation has a mean value of $655 \mathrm{~mm}$ throughout the entire study area (in Africa, there are significant contrasts of humidity - there are both very wet and extremely dry areas), while in the distribution area of this species the mean of this variable is $1190 \mathrm{~mm}$. For the orange form the mean is $1275 \mathrm{~mm}$ and $1093 \mathrm{~mm}$ for the red one.

\section{The climatic preferences}

Because of the continental range used in the model, the most important factors affecting species distributions were climate variables. By comparing the potential species distribution to the Köppen-Geiger climate classification, the possible climatic preferences of this species have been inferred (see Discussion).

By assigning mean temperature and mean total precipitation for each month to the locations of $P$. rhadamanthus, pronounced seasonal changes of climate of these areas have been observed (Figure 9). Climatic diagrams show a clear correlation between the decrease of temperature and amount of precipitation. What can also be observed is that the amount of precipitation is clearly decreasing in the southern hemisphere in winter and increasing during the summer, which is typical for the tropical savanna climate. 


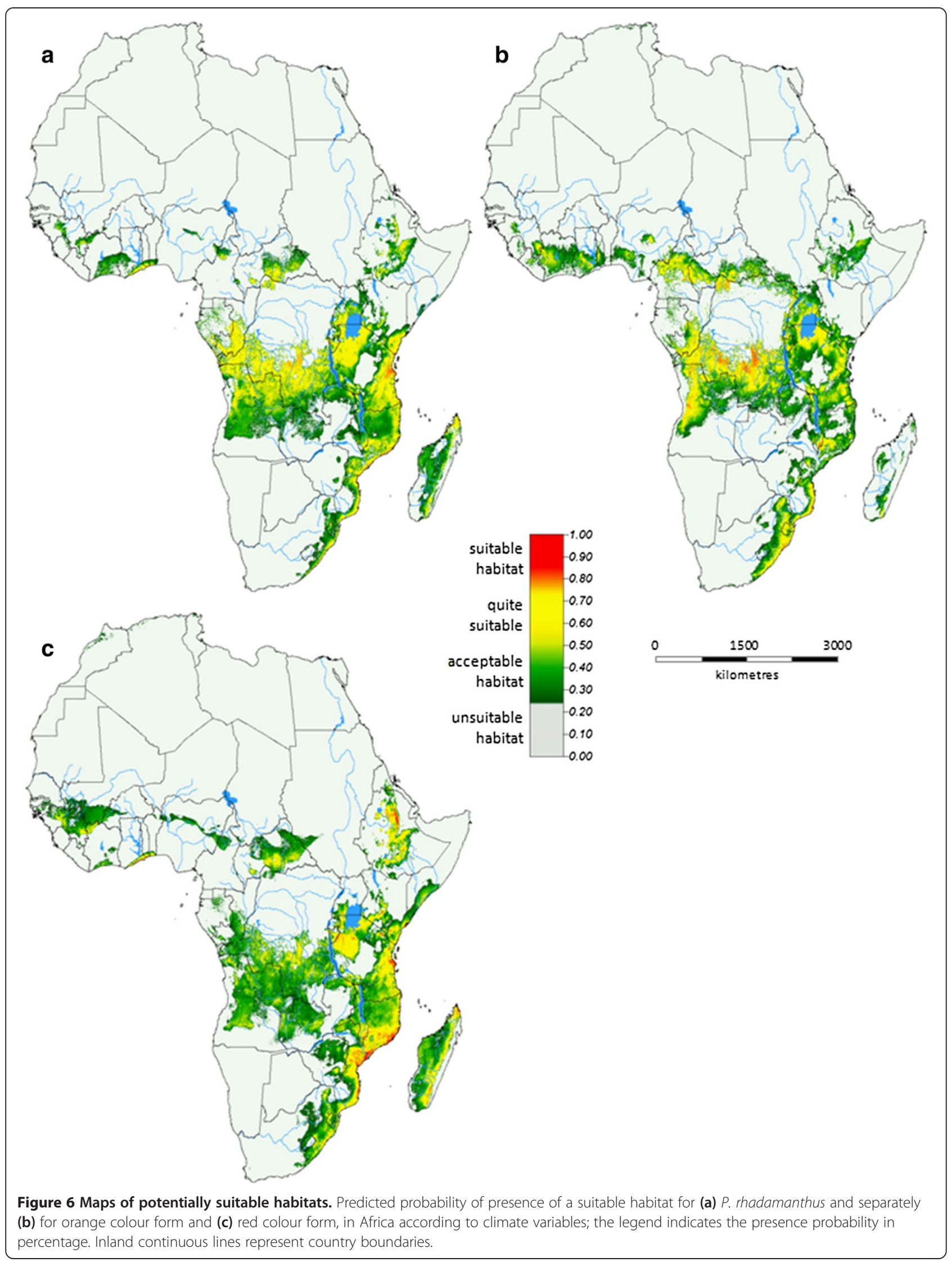




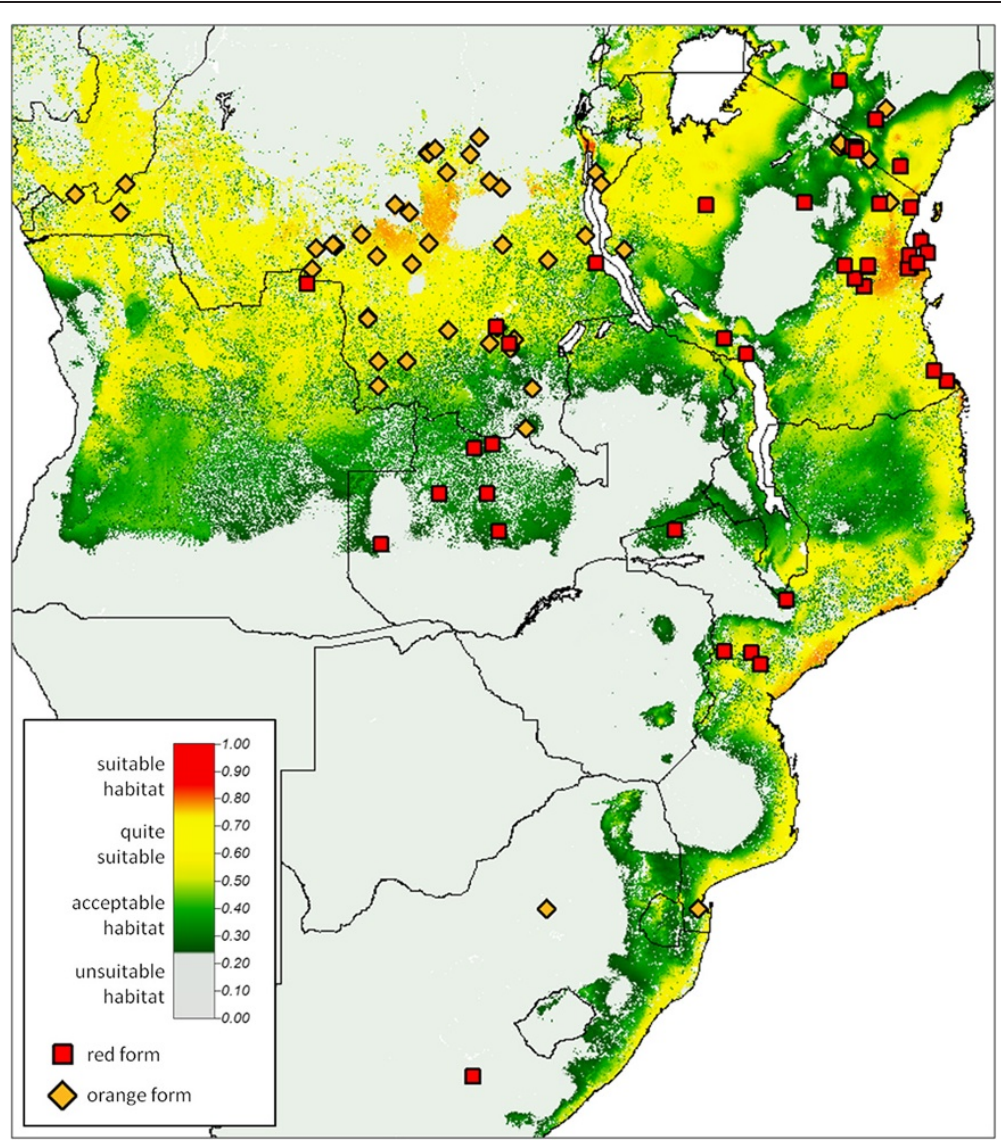

Figure 7 Known distribution points for $P$. rhadamanthus on the background of predicted suitable habitats. Distribution points divided into an orange and red colour form.

\section{Discussion}

Studies on some aspects of the biology of the genus Platymeris Laporte, 1833 were conducted in the laboratory and concerned two species: P. rhadamanthus Gerst. (Edwards, 1961, 1962a,b) and P. biguttatus (L.) (Edwards, 1982, Li et al., 2010). This research helped to understand the behaviour of these species in captivity, but the biology of $P$. rhadamanthus in the environment, and the habitat where the species occurs is unknown.

In Africa there are obvious geographical obstacles which limit the possibility of carrying out expeditions and of collecting material from such sites. It is also important to notice that such expeditions all over the world were often concentrated around the existing roads as well as towns and villages (Kadmon et al., 2004; see Loiselle et al., 2008 for a discussion of the samples which are biased with respect to accessibility). On the other hand, however, there were also researchers who had the courage to explore the unknown and wild areas in search of plants or animals in which they were interested. In the case of exploration of Africa those "wild " expeditions were conducted several times (e.g. Schaum, 1862; Jeannel, 1919; Villiers, 1954), and so the species occurrence data is not solely concentrated in the vicinity of human settlements (but see also Soberón \& Peterson, 2004 for a discussion on using data from museums and herbaria).

Through the use of the ecological niche modelling method habitat-suitability predictions have been made, providing some new information about $P$. rhadamanthus. As far as possible, it was attempted to reduce the correlation of used layers through the use of several statistical methods. Moreover, many specimens were collected from the same location and therefore in order to avoid model disturbances by strong intercorrelations, unnecessary strengthening of points was avoided (see Veloz, 2009).

As noted by Dungan et al. (2002), scale is very important in ecological or biogeographical studies which are based on modelling. The model was built with climatic, elevation and vegetative cover types data layers and employed the continental range, which mainly allowed for conclusions about the possible climatic preferences of the species. The climate variables used in the modelling show the possible tolerance ranges of this species for temperatures and precipitations. Finally, elevation data proved not to be important to the model, while the effects of the use of vegetative cover types data in ecological niche modelling 

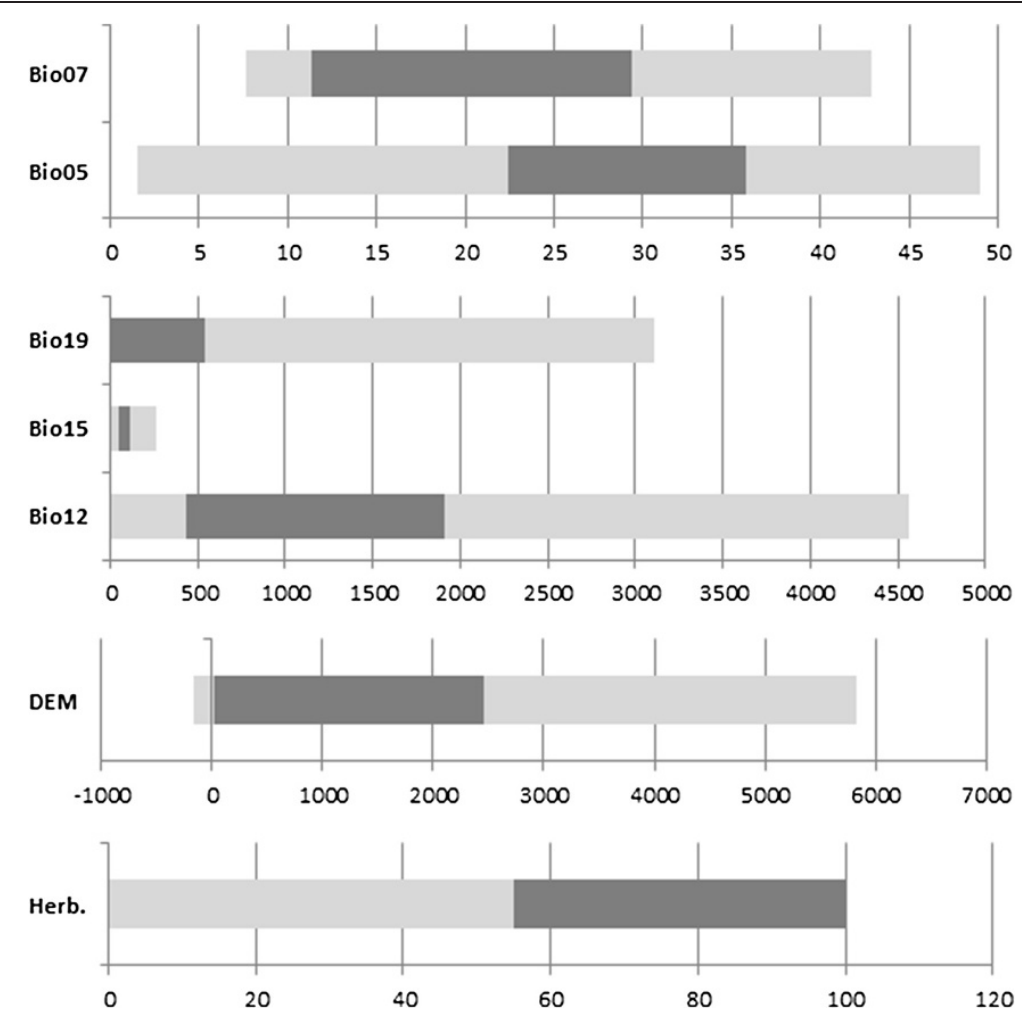

Figure 8 Projected niche space on the background of Africa. The dark gray bars and light gray bars represent the range of the variables in the potential distribution area and entire study area respectively for $P$. rhadamanthus. Because of the scale of variables, the temperature, precipitation, height above sea level and participation of herbaceous vegetation are presented separately.

were discernible. An additional use of a vegetative cover types layer as a predictor allowed to improve the performance of the model and allowed to specify areas of the same type of climate. Thus this variable may on the one hand reduce the range of the species, but on the other hand it helps to better characterize the habitat.

However, it was also discovered that by modelling the species as a whole and modelling of both colour forms separately, the arrangement of colour forms and their potential distribution is different. As a result of climate data, the red form (Figure 1c) seems to prefer areas with slightly higher temperatures in the warmest month and quarter of the year, but also the minimal temperatures are lower in the coldest month and quarter of the year than in case of the orange form (Figure 1b). What is more, for areas where the occurrence of the red form was localized, the average annual precipitation is smaller. Thus, the red form of $P$. rhadamanthus inhabits areas where the climate is warmer and drier than in the case of orange form of this species. The jackknife test showed that for the orange form herbaceous vegetation and then precipitation of warmest quarter (Bio18), are the variables which have the most useful information by themselves. For the red form, in turn, these variables are precipitation of coldest quarter (Bio19) and annual precipitation (Bio12), and these same values in reverse are the variables that decrease the gain the most when they are omitted. In the case of orange form, Bio18 and Bio12 have a significant portion of information not contained in the other variables. Potentially suitable habitats for the orange form of the described species were indicated mostly in the southern half of Congo and the Democratic Republic of Congo (the northern part near the border with Central African Republic), southwest part of Angola, southern half of Central African Republic, central part of Cameroon, almost the whole area of Tanzania (excluding the central part), small parts of south of Kenya, south of Uganda, Malawi (mostly the southern part and close to Lake Malawi), southeast coast of Mozambique and central part near Malawi, eastern coast of South Africa, Swaziland, and also some parts of Guinea, Liberia, Côte d'Ivoire, Ghana, Togo and Nigeria. For the red form those habitats were indicated in central parts of Ethiopia, central and south parts of Kenya, almost the whole area of Tanzania (excluding the central part), Burundi, east of Rwanda, mostly south of Malawi, eastern coast and central part of Mozambique, coast of Ghana, Togo and Benin, and also some parts of Guinea, Côte d'Ivoire, Central African Republic, Gabon, Congo, Democratic Republic of the Congo, Angola, Zambia, Zimbabwe, South Africa (mostly the eastern part), Swaziland and 

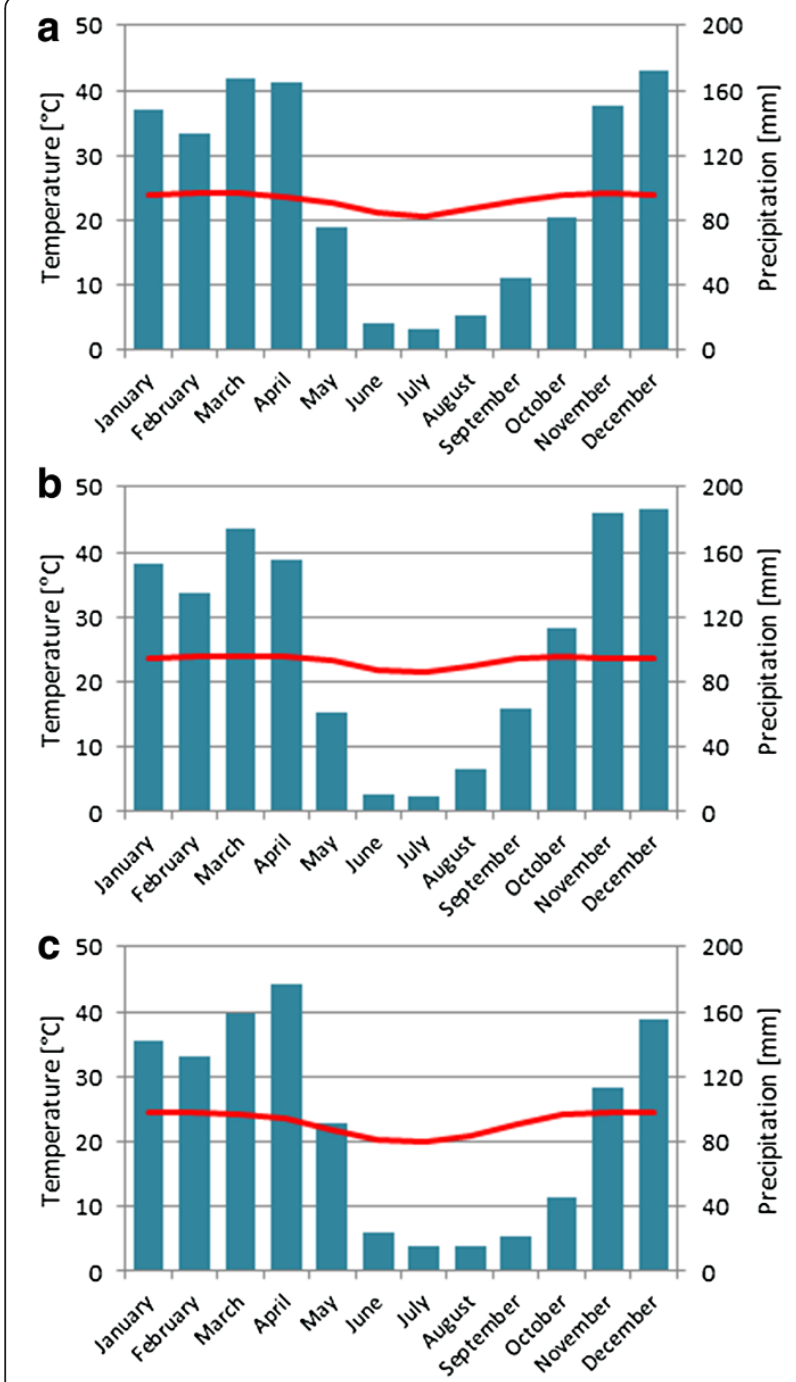

Figure 9 Climate diagrams of the distribution of air temperature and precipitation. The climatic diagrams for (a) P. rhadamanthus and separately (b) for orange colour form and (c) red colour form. Line show the temperature distribution during the year and bars represent the distribution of precipitation throughout the year. For each month, the average value from all known locations of this species is given.

Somalia. Thus, when we treat colour forms separately, their ranges and potential ecological niches are a little bit different from each other.

There are also different heights on which they were found. The red form has been found at maximum about 1560 meters a.s.l. and the orange form has been found at maximum about 2450 meters a.s.l. Nevertheless, we have to clearly state that the average height for the red form amounted to 705 meters a.s.l., and for the orange one it was 840 meters, so actually this difference is not very big.

For this species, most of the suitable habitats suggested by the model lie in the area of tropical savanna climate, where for every month of the year the monthly mean temperature is above $18^{\circ} \mathrm{C}\left(64^{\circ} \mathrm{F}\right)$ and there are pronounced dry seasons - with precipitation at a level below $60 \mathrm{~mm}$ in the driest month. Many suitable habitats have also been modelled in the area of the subtropical highland variety of the oceanic climate and humid subtropical climate. In Africa these types of climates have milder temperatures because of warm and wet flow from the tropics, and the warmest month has above $22^{\circ} \mathrm{C}\left(71.6^{\circ} \mathrm{F}\right)$. In the winter the temperatures do not drop as low as in many other regions within the similar types of climates. Some suitable habitats are also present in limited areas of hot semi-arid climate, mainly in Ethiopia as well as Kenya and Tanzania. In this kind of climate the summers are hot (sometimes very) and winters are mild to warm, while the precipitation not very large, but there are seasonal effects of monsoons and the short wet season is well-defined.

Since this species is predatory and has several different species of victims, it was difficult to use biotic interactions in our model. Nevertheless, after analyzing the variables it was concluded that this species prefer open areas with small participation of tree vegetation, which probably results from the food preferences of its victims. At this point it should be considered whether the potential ecological niche that is presented in this paper also reflects the preferred conditions for the victims of the described predator. Therefore its preferences will depend largely on its victims, and the tolerance to climatic factors may be much wider.

The results of the modelling are supported by additional materials (in the methods marked by *). These materials confirm the obtained results, even though they have not been used in the modelling process. This is due to the fact that the description of these specimens contained only the country in which they were collected, without the exact location. The model clearly indicated the presence of favorable environmental conditions in Gabon and Senegal, where specimens were also collected - which further confirms the accuracy of the resulting model the potential distribution of the species.

It should also be noted that the model suggests suitable conditions for this species in the area of Madagascar. Geographical barrier does not allow it to penetrate to the island, but its introduction could threaten the local fauna - in such case it could be considered as an invasive species. However, we should remember that the species could be absent in a given location, even if it was suggested by the model as potentially suitable (Anderson, 2003; Martínez-Meyer, 2005). That happens because it is not possible to take into account all the potential environmental factors, such as e.g. lack of prey resources or even presence of other predator. Therefore, it would be worthwhile to carry out some field studies to test the hypothesis of a potential distribution, and to obtain data on the ecology of this species. 


\section{Conclusions}

$P$. rhadamanthus is redescribed and designation of lectotype and paralectotype is carried out. So far it was only known that this species occurs in widely understood tropical Africa. Thanks to the museum data on the occurrence of the species the ecological niche modelling methods can be performed. The use of this method resulted in new and valuable information of the potentially suitable habitat, the possible range of distribution of the species and its climatic preferences.

\section{Additional files}

\section{Additional file 1: Detailed list of other examined materials, which} also provided the information about occurrence localities.

Additional file 2: Maxent model output and environmental variable correlations.

Additional file 3: Detailed maps of potentially useful niche for $P$. rhadamanthus and its colour forms.

\section{Abbreviations}

(ZMB): Museum für Naturkunde; Berlin: Germany.

\section{Competing interests}

The authors declare that they have no competing interests.

\section{Authors' contributions}

DC performed taxonomic analysis and collected data on the occurrence of specimens; drafted the manuscript. AB-N performed ecological niche modelling; analyzed the data on the occurrence; analyzed climatic preferences of the species; drafted the manuscript. Both authors read and approved the final manuscript.

\section{Acknowledgements}

We are very grateful to E. De Coninck (MRAC), J. Constant (IRSNBG), J. Deckert (ZMB), E. Guilbert (MNHN), G. Lindberg (NHRS), M. Webb (BMNH) and $\mathrm{H}$. Zettel (NMW) for all their kind help and hospitality during the first author's visit in the collections. We also want to express special thanks to $Ł$. Junkiert for the drawings and Z. Sierotnik for language correction.

Received: 30 August 2013 Accepted: 16 January 2014

Published: 4 February 2014

\section{References}

Anderson RP (2003) Real vs. artefactual absences in species distributions: tests for Oryzomys albigularis (Rodentia: Muridae) in Venezuela. J Biogeogr 30:591-605

Araújo MB, Whittaker RJ, Ladle RJ, Erhard M (2005) Reducing uncertainty in projections of extinction risk from climate change. Global Ecol Biogeogr 14:529-538

Distant WL (1878) Notes on African Hemiptera-Heteroptera. Entomol Mon Mag 15:99-100

Distant WL (1902) Rhynchotal notes. XIV. Heteroptera: Families: Hydrometridae, Henicocephalidae, and Reduviidae (part). Ann Mag Nat Hist 10(7):173-194

Dungan JL, Perry JN, Dale MRT, Legendre P, Citron-Pousty S, Fortin M-J, Jakomulska A, Miriti M, Rosenberg MS (2002) A balanced view of scale in spatial statistical analysis. Ecography 25:626-640

Edwards JS (1961) Action and composition of saliva of an assassin bug, Platymeris rhadamanthus Gerst. (Hemiptera: Reduviidae). J Exp Biol 38:61-77

Edwards JS (1962a) Spitting as a defensive mechanism in a predatory reduviid, vol 4. Report on the 11th International Congress of Entomology, Vienna, pp 259-263

Edwards JS (1962b) Observations on the development and predatory habits of two reduviids (Heteroptera), Rhynocoris carmelita Stål and Platymeris rhadamanthus Gerst. Proc R Entomol Soc Lond 37(A):89-98

Edwards JS (1982) Platymeris biguttata (L.) (Hemiptera: Reduviidae) in Britain with some notes on its biology. Entomol Mon Mag 118:45-46
Elith J, Graham CH, Anderson RP, Dudik M, Ferrier S, Guisan A, Hijmans RJ, Huettman F, Leathwick JR, Lehmann A, Li J, Lohmann LG, Loiselle BA, Manion G, Moritz C, Nakamura M, Nakazawa Y, Overton JM, Peterson AT, Phillips SJ, Richardson K, Scachetti-Pereira R, Schapire RE, Soberón J, Williams SE, Wisz MS, Zimmermann NE (2006) Novel methods improve prediction of species' distributions from occurrence data. Ecography 29:129-151

Fielding AH, Bell JF (1997) A review of methods for the assessment of prediction errors in conservation presence/absence models. Environ Conserv 24:38-49

Gerstaecker CEA (1873) II. Gliederthiere (Insekten, Arachniden, Myriopoden und Isopoden). In: Baron Carl Claus von der Decken's Reisen in Ost-Afrika in den jahren 1859-1865. C.F. Winter'sche Verlagshandlung, Leipzig und Heidelburg, pp 1869-1879

GLOBE Task Team and others (1999) In: Hastings DA, Dunbar PK, Elphingstone GM, Bootz M, Murakami H, Maruyama H, Masaharu H, Holland P, Payne J, Bryant NA, Logan TL, Muller J-P, Schreier G, MacDonald JS (eds) The Global Land One-kilometer Base Elevation (GLOBE) Digital Elevation Model, Version 1.0. National Oceanic and Atmospheric Administration, National Geophysical Data Center, 325 Broadway, Boulder, Colorado 80305-3328, USA

Google Inc (2013) Google Earth, version 6.2.2.6613. Mountain View, CA, USA

Hansen MC, DeFries RS, Townshend JRG, Carroll ML, DiMiceli CM, Sohlberg RA (2003) Global Percent Tree Cover at a Spatial Resolution of 500 Meters: First Results of the MODIS Vegetation Continuous Fields Algorithm. Earth Interact 7(10):1-15

Hernandez PA, Graham CH, Master LL, Albert DL (2006) The effect of sample size and species characteristics on performance of different species distribution modeling methods. Ecography 29:773-785

Hijmans RJ, Cameron SE, Parra JL, Jones PG, Jarvis A (2005) Very high resolution interpolated climate surfaces for global land areas. Int J Climatol 25:1965-1978

Jeannel R (1919) Insectes Hémiptères, III. Henicocephalidae et Reduviidae. In: Voyage de Ch. Alluaud et R. Jeannel en Afrique Orientale (1911-1912). reśultats scientifiques, Lhomme, Paris

Jeschke JM, Strayerb DL (2008) Usefulness of Bioclimatic Models for Studying Climate Change and Invasive Species. Ann NY Acad Sci 1134:1-24

Kadmon R, Farber O, Danin A (2004) Effect of roadside bias on the accuracy of predictive maps produced by bioclimatic models. Ecol Appl 14:401-413

Laporte FL (1833) Essai d'une classification systematique de l'ordre des Hémiptères Hétéroptères, Latr. Mag Zool 1(ser 2):1-88, plus supplement

Li H, Zhao G, Cao L, Xu K, Cai W (2010) Taxonomic and bionomic notes on the white spot assassin bug Platymeris biguttatus (Linnaeus) (Hemiptera: Reduviidae: Reduviinae). Zootaxa 2644:47-56

Linnaeus C (1767) Systema Naturæ per regna tria naturæ, secundum classes, ordines, genera, species, cum characteribus, differentiis, synonymis, locis. Editio duodecima, reformata. Tomus II. Laurentius Salvius, Holmiae

Loiselle BA, Jørgensen PM, Consiglio T, Jiménez I, Blake JG, Lohmann LG, Montiel OM (2008) Predicting species distributions from herbarium collections: does climate bias in collection sampling influence model outcomes? J Biogeogr 35:105-116

Maldonado Capriles J (1990) Systematic Catalogue of the Reduviidae of the World (Insecta: Heteroptera). (Special edition of the Caribbean Journal of Science). University of Puerto Rico, Mayagüez, Puerto Rico

Martínez-Meyer E (2005) Climate change and biodiversity: some considerations in forecasting shifts on species' potential distributions. Biodivers Inform 2:42-55

Pearce J, Ferrier S (2000) Evaluating the predictive performance of habitat models developed using logistic regression. Ecol Model 133(3):225-245

Pearson RG, Raxworthy CJ, Nakamura M, Townsend Peterson A (2007) Predicting species distributions from small numbers of occurrence records: a test case using cryptic geckos in Madagascar. J Biogeogr 34:102-117

Peel MC, Finlayson BL, McMahon TA (2007) Updated world map of the Köppen-Geiger climate classification. Hydrol Earth Syst Sc 11:1633-1644

Phillips SJ, Anderson RP, Schapire RE (2006) Maximum entropy modeling of species geographic distributions. Ecol Model 190:231-259

R Development Core Team (2011) R: A language and environment for statistical computing, version 2.15.2. R Foundation for Statistical Computing, Vienna, Austria

SAGA Development Team (2013) System for Automated Geoscientific Analyses (SAGA), version 2.0.8. Institute of Geography at the University of Hamburg, Germany

Schaum HR (1862) Hemiptera, Halbflügler von Mossambique. In: Naturwissenschaftliche reise nach Mossambique auf befehl Seiner Majestät des königs Friedrich Wilhelm IV, in den jahren 1842 bis 1848 ausgeführt, von Wihelm C. H. Peters. G. Reimer, Berlin, pp 1-34, Vol. 5 

des Somalis. Hemiptera III-IV. - Reduviidae et Miridae. Annales de la Société entomologique de Belgique 50:20-29

Soberón J, Peterson AT (2004) Biodiversity informatics: managing and applying primary biodiversity data. Philos Trans R Soc Lond B Biol Sci 359:689-698

Warren DL, Glor RE, Turelli M (2008) Environmental niche equivalency versus conservatism: quantitative approaches to niche evolution. Evolution 62:2868-2883

Williams GJ (2011) Data Mining with Rattle and R: The Art of Excavating Data for Knowledge Discovery. Use R! series, Springer-Verlag, Heidelberg

Veloz SD (2009) Spatially autocorrelated sampling falsely inflates measures of accuracy for presence-only niche models. J Biogeogr 36:2290-2299

Villiers A (1954) Exploration du Parc I'Upemba. Henicocephalidae et Reduviidae (Hemiptera). Mission G.F. de Witte. Institut des Parcs Nationaux du Congo Belge, Brussels, fascicule 18:1-54

Zhu G, Bu W, Gao Y, Liu G (2012) Potential geographic distribution of Brown Marmorated Stink Bug invasion (Halyomorpha halys). PLoS ONE 7(2):e31246

doi:10.1186/1810-522X-53-8

Cite this article as: Chłond and Bugaj-Nawrocka: Model of potential distribution of Platymeris rhadamanthus Gerstaecker, 1873 with redescription of species. Zoological Studies 2014 53:8.

\section{Submit your manuscript to a SpringerOpen ${ }^{\circ}$ journal and benefit from:}

- Convenient online submission

- Rigorous peer review

- Immediate publication on acceptance

- Open access: articles freely available online

- High visibility within the field

- Retaining the copyright to your article

Submit your next manuscript at $>$ springeropen.com 